\title{
DISCUSSÃO ACERCA DO ENSINO POR COMPETÊNCIAS: PROBLEMAS E ALTERNATIVAS
}

\author{
ELIO CARLOS RICARDO
}

Professor da Faculdade de Educação da Universidade de São Paulo elioricardo@usp.br

\begin{abstract}
RESUMO
As competências se tornaram parte do discurso educacional, principalmente após a publicação das Diretrizes Curriculares Nacionais para o Ensino Médio e dos Parâmetros Curriculares Nacionais pelo Ministério da Educação. Todavia, tem-se observado que sua compreensão não é clara. Este artigo apresenta e discute alguns problemas e alternativas acerca da noção e da lógica das competências. Além disso, questiona as práticas e os saberes docentes.

ENSINO MÉDIO - COMPETÊNCIAS - COMPETÊNCIA DO PROFESSOR - PRÁTICA DE ENSINO
\end{abstract}

\begin{abstract}
A DISCUSSION ABOUT LEARNING COMPETENCES: PROBLEMS AND ALTERNATIVES. Competences became part of the educational discourse, mainly after the issue of the National Curriculum Guidelines for Secondary Education and the National Curriculum Parameters by the Brazilian Ministry of Education. However, it has been observed that their comprehension is not clear. This paper presents and discusses some problems and alternatives about the notion and the logic of competences. Moreover, the practices and teacher knowledge are questioned.

SECUNDARY EDUCATION - SKILLS - TEACHER BACKROUND - EDUCATIONAL PRACTICE
\end{abstract}


O Ministério da Educação publicou em 2006 as Orientações Curriculares para o Ensino Médio (Brasil, 2006), as quais seguem, em linhas gerais, a forma dos Parâmetros Curriculares Nacionais - PCN e PCN+ (Brasil, 1999, 2002). Ou seja, cada um dos componentes curriculares é tratado em separado e permanece a divisão das três áreas do conhecimento: Linguagens, Códigos e suas Tecnologias; Ciências da Natureza, Matemática e suas Tecnologias; Ciências Humanas e suas Tecnologias.

Todavia, se quanto à forma há semelhanças, o mesmo não ocorre com os conteúdos dos documentos. Os primeiros, PCN e PCN+, tinham como referência as Diretrizes Curriculares Nacionais para o Ensino Médio DCNEM -, de onde herdaram, entre outras coisas, os princípios pedagógicos da interdisciplinaridade e da contextualização para a estruturação de um currículo por competências. As Orientações Curriculares de 2006 não seguem necessariamente as mesmas diretrizes e, portanto, os textos de cada um dos componentes curriculares diferem em seus encaminhamentos teóricometodológicos. Enquanto alguns desses componentes seguem na direção de implementar um ensino por competências, outros sugerem seu abandono.

Muitas discussões poderiam surgir de um estudo analítico-comparativo desses documentos, mas isso excederia o objetivo deste artigo'. O que permanece, passados mais de dez anos desde a Lei de Diretrizes e Bases - LDB -, de 1996, a qual desencadeou a elaboração desses documentos, é que todos eles ainda se encontram distantes do contexto escolar. Ou seja, sua implementação ainda não ocorreu (Ricardo, 2002). Além disso, alguns pressupostos básicos desses documentos permanecem pouco claros aos professores, até mesmo na formação inicial, conforme verificaram Santos, Campos e Almeida (2005) e Ricardo e Zylbersztajn (2002, 2007, 2008). Pode-se dizer que o principal deles é a noção de competências, ou o ensino por competências, o qual já foi alvo de muitas críticas às DCNEM. Mas, seria possível compreender a noção de competências para além de uma subordinação da escola ao mercado de trabalho ou de uma privatização do indivíduo? Ou ainda, poderia a noção de competências contribuir para a adesão dos alunos ao projeto formativo da escola?

I. Alguns comentários a respeito desse documento podem ser encontrados em Ricardo, Custódio, Rezende Jr. (2008). 
Assim, sem criar dicotomias entre opiniões contrárias e favoráveis, o objetivo deste artigo é expor os principais problemas identificados por alguns autores em relação à institucionalização de um ensino por competências para, em seguida, apresentar outros autores que veem essa proposição como uma possível alternativa ao fracasso escolar. Entretanto, em ambos os casos são questionados o papel da escola, os saberes e as práticas do professor e os conteúdos de ensino. Ao mesmo tempo em que os pressupostos e orientações contidas nos documentos oficiais parecem ser interpretados de muitas maneiras nas escolas, segundo alerta Silva (2008), torna-se fundamental discuti-los e compreendê-los, a fim de explorar os limites e possibilidades das propostas se transformarem em efetivas mudanças no cenário escolar e, se implementadas, para qual caminho estariam apontando.

\section{O ENSINO POR COMPETÊNCIAS E SEUS PROBLEMAS}

As discussões sobre um ensino por competências, tanto na formação geral como na profissional, com ênfase para esta última, surgem nas décadas de 1960 e 1970, segundo Ropé e Tanguy (1997), dependendo de cada país. Para as autoras, desde o início, a noção de competências esteve associada à ideia de formação e tende a substituir a noção de saberes na educação geral e a noção de qualificação na formação profissional, embora não sejam sinônimos².

Uma primeira interpretação para as competências seria a de uma qualificação acrescida de um saber-fazer, incluindo-se atitudes do empregado no ambiente de trabalho. Para Durand, isso acarreta uma arbitrariedade no estabelecimento dos contratos de trabalho, que seriam estruturados não apenas sobre a qualificação, mas na capacidade de torná-la disponível na empresa e em benefício desta, uma vez que é o empregador que irá avaliar as competências. Desse modo, as relações de trabalho serão estabelecidas "pelo mercado e longe de toda a proteção das convenções coletivas - o que coloca a individualização da relação salarial no coração do novo dispositivo" (200। , p. 2I3). Além disso, o vínculo de aspectos subjetivos à qualificação poderia levar a políticas

2. Ropé e Tanguy (1997) preferem utilizar o termo "noção" para designar as competências, a fim de reconhecer seu caráter extensivo e polissêmico e que pode indicar mudanças sociais com usos diferenciados em lugares e épocas distintas. 
empresariais reprodutoras de situações de exclusão social dos trabalhadores marginalizados na divisão social do trabalho (Arruda, 2000). Acrescente-se a isso o surgimento de comunidades de comércio internacionais que exercem certa padronização nas regras de produção e concorrência e, por conseguinte, nas competências profissionais.

Em certos casos, aspectos da personalidade dos trabalhadores, como responsabilidade, iniciativa, comunicação, empreendedorismo, são enfatizados em detrimento de qualificações técnicas, pois sobrevivem à automatização e parecem responder melhor às crises. Ou seja, espera-se uma formação para o trabalho de modo geral e não para uma ocupação específica. Esta última caracterizaria melhor o conceito de qualificação. Isso desloca a responsabilidade da formação para o sujeito. A emergência da noção de competências nessa perspectiva e a não percepção da qualificação como um processo histórico e social enfraquecem as conquistas coletivas e põem em conflito interesses pessoais e coletivos, liberando o Estado de regulamentações, uma vez que se fortalecem as relações entre empregado e empresa.

Segundo Ramos (200I), ainda seria possível, no entanto, estabelecer significados à noção de competências favoráveis aos trabalhadores, uma vez que o deslocamento conceitual da qualificação às competências ainda não estaria consolidado definitivamente em favor das classes dominantes, pois se trata de um fenômeno histórico. $\bigcirc$ mesmo não ocorre com o conceito de qualificação, o qual é bem consolidado na Sociologia e seus significados se construíram historicamente. Ao mesmo tempo em que se atribui a origem da noção de competências à educação técnico-profissional, sua transposição para a educação geral, assim como suas críticas, exigem cuidados, pois são formações distintas, ainda que estejam imersas em um mesmo contexto histórico e sociocultural. Nesse sentido, ambas as formações buscam responder de diferentes maneiras às mudanças sociais. Conforme Ropé, Tanguy (1997), Ramos (200 I) e Arruda (2000), um dos fatores mais influentes na institucionalização das competências na formação geral e profissional foram as transformações nas relações de produção.

Um dos argumentos em favor das competências era a aproximação entre escola e trabalho, conforme se verifica inclusive nas DCNEM. É uma tentativa de mudar a relação entre a teoria e a prática, entre o geral e o específico. Entretanto, a educação geral e a formação técnico-profissional, além 
de outras diferenças, atribuem distintos status aos saberes e às práticas. Isso implica diferentes status na legitimação dos saberes que serão objetos dessas formações, bem como suas referências.

$\mathrm{Na}$ formação técnico-profissional a relação entre a empresa e a escola é bem mais estreita e se pode dizer que as ambiguidades a respeito do termo competências são menores. Para Ropé e Tanguy (1997)33, aceita-se uma definição possível para as competências como sendo um "saber-fazer operacional validado". Tal definição, todavia, esconde o que os críticos à noção de competências chamam "lógica das competências", a qual limitaria a autonomia dos trabalhadores e propõe uma nova ordem nas relações de trabalho.

Ao assumir as competências como um "saber-fazer operacional validado", entende-se que as qualificações adquiridas na profissão são temporárias, ao contrário de um diploma, que certifica um título. Este, porém, não é mais suficiente para a empregabilidade. ○ "saber-fazer", nesse caso, envolve não só os conhecimentos adquiridos, mas também as experiências acumuladas ao longo da atividade profissional, e o adjetivo "operacional" implica que tais saberes serão aplicáveis em uma organização/empresa. Esses saberes terão que ser "validados". Ou seja, serão confirmados pela formação e pelo controle das funções exercidas na empresa, pois apenas a titulação, praticamente entendida como a qualificação, não é mais garantia de competência.

Ao mesmo tempo em que isso desloca a formação também para dentro da empresa, esta reconhecerá as qualificações adquiridas pelo empregado e irá classificá-lo e remunerá-lo. O lado perverso dessa nova forma de relação se consolida em uma individualização do sujeito. Segundo Machado (2002), essa dimensão reguladora das relações entre empregado e empregador, consequência das mudanças nos sistemas produtivos e na mundialização do capital, acaba criando nos indivíduos conformismos sociais, "capazes de levá-los à resignação e à aceitação, como inevitáveis, de situações tais como a precariedade do trabalho, a incerteza do futuro profissional e a individualização da responsabilidade com relação à sobrevivência no mercado de trabalho" (Machado, 2002,

3. Vale destacar que os trabalhos de Françoise Ropé e Lucie Tanguy são a base de vários livros e artigos publicados no Brasil a respeito de competências, principalmente na esfera da Sociologia do trabalho. Essas autoras dão ênfase maior à institucionalização das competências na França. Philippe Perrenoud também é referência comum, predominantemente na Sociologia do currículo. 
p. 95). Transpor essa mesma lógica para o sistema educacional e de formação profissional seria subordinar-se às exigências do mercado, o qual poderia estabelecer inclusive os padrões de qualidade. Isso poderia reduzir o ensino a um treinamento, com o qual Ramos (200l) se opõe ao alertar que nessa ótica "a função educativa começa a ser marcada também por uma perspectiva individualizante e adaptativa da sociedade às incertezas da contemporaneidade" (Ramos, 200I, p. 131). Para a autora, certo determinismo tecnológico, que sustenta os argumentos dos documentos oficiais do MEC em favor de uma formação para o trabalho e a cidadania, encobriria um fatalismo:

Diluem-se todas as expectativas de se olhar o mundo por um outro viés, de se contestar o que parece instituído e único, de se efetivar a organização coletiva que transcenda aos ideais personalistas, subjetivistas e/ou produtivistas, mas que apontem no sentido da construção de projetos sociocoletivos emancipadores. (Ramos, 200I, p. 135)

Embora não se possa atribuir com exatidão a adesão das Diretrizes Curriculares Nacionais à "lógica das competências", causa um certo incômodo quando esses documentos assumem que:

...nas condições contemporâneas de produção de bens, serviços e conhecimentos, a preparação de recursos humanos para um desenvolvimento sustentável supõe desenvolver a capacidade de assimilar mudanças tecnológicas e adaptar-se a novas formas de organização do trabalho. (Brasil, 1999, p.73)

Um possível desdobramento dessa concepção é que o homem se torna um mero recurso, "recurso humano", deixando de ser sujeito e passando a ser um objeto do capital moderno. É a empresa e na empresa que se dará a validação das competências, com vistas à classificação e à remuneração. Assim, a lógica das competências pode ser sintetizada em uma frase: é o indivíduo que faz o seu cargo e o seu salário (Tanguy, 1997). Em certo sentido isso pode indicar uma autonomia ao trabalhador e é plausível esperar que haja um aumento da sua escolaridade e uma valorização dos seus saberes práticos. Entretanto, pode haver uma falsa autonomia que acabaria por levar a um enfraquecimento das classes: 
O reconhecimento e a avaliação das competências, fundamentados em processos de negociação individualizada, contribuiriam para moldar uma certa concepção de sujeito e de autonomia, voltada para o desenvolvimento da capacidade adaptativa e para enfraquecer a solidariedade informada pelos interesses coletivos como consequência do aumento da competição entre os indivíduos. (Machado, 1998, p. 84)

A adoção de tal modelo também na educação geral, chamado por Machado ( 1998 ) "modelo de competências", opõe-se a um projeto educacional emancipador $^{4}$, pois mesmo considerando os distintos pontos de partida dos alunos, conforme ressaltam as DCNEM, não há garantias de que os pontos de chegada serão iguais. Além de um isolamento das categorias profissionais e de um conformismo diante das diferenças de salário, a lógica das competências faz ver como inevitáveis a instabilidade do emprego e a precariedade do trabalho, decorrentes das imposições do mercado e das transformações econômicas atuais. Cresce, portanto, a visão pragmática, utilitária e imediatista das formações e as expectativas pessoais são intimidadas pelas incertezas. A perda de direitos e benefícios sociais, segundo Deluiz (200I), passa a ser a "regra do jogo" na conjuntura atual.

Ao orientar a organização dos currículos e dos programas escolares, a noção de competências, ou a chamada "pedagogia das competências" (Ropé, Tanguy, 1997; Ramos, 2001 ; Machado, 1998), faz com que as escolas se abram para o mundo econômico e busquem atribuir um sentido prático aos saberes escolares. Poder-se-ia dizer que a transposição dessa noção para a educação geral teria um princípio de busca de justiça social, pois muitos alunos que fracassam na escola têm êxito no ensino profissional. No entanto, a lógica das competências aponta também para outro caminho, qual seja, o da privatização do indivíduo, que passa a ser tão livre quanto lhe for permitido. $E$, se antes a escola era vista como uma promessa de emprego, agora passa a ser vista como um caminho para a empregabilidade, sob a responsabilidade de cada um. Ou seja, o que antes seria um projeto de sociedade, passa a ser encarado como um projeto de indivíduos adaptáveis. Em suma, esse cenário possibilita o surgimento de uma nova ética:

4. Assume-se aqui a perspectiva de Paulo Freire para esse termo. 
Parece haver uma atrofia dos sujeitos coletivos e da própria sociedade civil, cujo sentido volta a ser de espaço em que se estabelecem as relações privadas, sob a ética da liberdade individual. Sob essa concepção, o indivíduo encerra-se como realidade completa em si mesma e estabelece o interesse particular como finalidade última de todas as suas ações. (Ramos, 200 I, p.302)

Frequentemente se encontra nas definições para as competências um viés cognitivo de adaptação à realidade, ou de contínua apreensão da realidade e de novas competências visando a novas adaptações, raramente para a superação ou, ainda, a transformação dessa realidade. Dessa forma, a construção do conhecimento e a adaptação do indivíduo ao meio se confundem. Talvez, por essa razão, é comum associar a noção de competências com o princípio do "aprender a aprender" sem uma compreensão precisa. Isso poderia favorecer a implementação da lógica das competências e, ao mesmo tempo, levar a um esvaziamento dos conteúdos escolares.

Esse esvaziamento ocorreria na medida em que há um deslocamento da valorização atribuída à aprendizagem realizada pelo indivíduo sozinho em detrimento da aprendizagem pela apreensão dos saberes elaborados. $\bigcirc$ conhecimento torna-se exclusividade do indivíduo e circunstancial. Nesse sentido, a compreensão da realidade será sempre parcial e descontínua, de maneira que as ações desses indivíduos passam a ter como referência fundamental seus interesses e necessidades particulares.

Quando a eficácia assume status de verdade e as representações subjetivas passam a substituir o conhecimento objetivo, há, no limite, uma recusa à razão, e nenhum pensamento corresponde mais à realidade que outro, uma vez que a escola se reduz ao confronto, à negociação e ao compartilhamento de discursos e trocas de experiências. Isso pode conduzir a um subjetivismo e a um relativismo epistemológico 5 .

\section{O ENSINO POR COMPETÊNCIAS COMO ALTERNATIVA}

Um dos principais autores que apresentam o ensino por competências como uma possível alternativa ao fracasso escolar é Philippe Perrenoud. Isso se

5. Adotam-se aqui as definições de Juan Hessen (1994) para o subjetivismo e o relativismo. 
torna mais relevante na medida em que há vários livros e artigos de sua autoria traduzidos para a língua portuguesa. Paradoxalmente, isso não significa que suas ideias sejam bem compreendidas e tampouco implementadas na escola, conforme ressaltam Silva (2008), Ricardo (2002); Ricardo, Zylbersztajn (2002, 2007, 2008). Uma das razões é que Perrenoud se apropria de vários conceitos da didática das ciências da escola francesa ${ }^{6}$ e que são verdadeiras caixas-pretas ${ }^{7}$ para a maioria dos seus leitores, a saber, a noção de "transposição didática", de "contrato didático", as "práticas sociais de referência", os "objetivos-obstáculos", os "campos conceituais" e os "esquemas-em-ação", para citar alguns exemplos. Perrenoud não trata especificamente do ensino das ciências, mas da formação em geral, o que poderia resultar em uma transposição para outras áreas de conceitos e teorias com fortes matizes no ensino de ciências e, por conseguinte, provocar uma compreensão aparente de suas ideias.

Diferentemente das críticas anteriores, o conceito de competências de Perrenoud se aproxima de um enfoque didático, mais especificamente para a formação geral. Esse autor atribui vários conceitos às competências, mas a ênfase repousa sobre a mobilização de recursos cognitivos. Uma dessas definições revela a diversidade de requisitos para se construir uma competência:

Define-se uma competência como a aptidão para enfrentar uma família de situações análogas, mobilizando de uma forma correta, rápida, pertinente e criativa, múltiplos recursos cognitivos: saberes, capacidades, microcompetências, informações, valores, atitudes, esquemas de percepção, de avaliação e de raciocínio. (Perrenoud et al., 2002, p. 19)

Em outra definição, Perrenoud afirma que as competências são "uma capacidade de agir eficazmente em um determinado tipo de situação, apoiada em conhecimentos, mas sem limitar-se a eles" (Perrenoud, 1999, p.7). Uma competência que se manifesta na execução de uma tarefa não é, portanto, a mera aplicação de conhecimentos memorizados, envolve também um julgamento da pertinência dos recursos disponíveis e sua integração com discernimento em tempo real. Assim, a construção de competências é inseparável da

6. A rigor, trata-se dos países de língua francesa.

7. Metáfora que indica um objeto de conteúdo desconhecido ou de conhecimento superficial. 
formação de esquemas de mobilização, que se constituem e se consolidam em treinamentos ${ }^{8}$ associados a uma postura reflexiva. Tais treinamentos envolvem experiências renovadas e disponibilidade para a análise, uma vez que o mero acúmulo de conhecimentos não garante sua integração e mobilização.

Isso não significa, todavia, que só se aprende fazendo. Mesmo as competências mais práticas têm em sua estrutura saberes incorporados ao longo de um trabalho intelectual. Competências dessa natureza são, muitas vezes, atribuídas ao talento pessoal ou à experiência. Essa concepção sugere a falta de consciência da necessidade de métodos e de ferramentas intelectuais para a construção de novos saberes ou de que algumas competências aprendidas anteriormente são mobilizadas de modo natural. Ao mesmo tempo em que o acúmulo de conhecimentos não garante a sua mobilização em situações complexas, é condição necessária, pois sem recursos a mobilizar não se constroem competências. $\bigcirc$ contrário também é verdadeiro, uma vez que se existem os recursos, mas não são mobilizados com discernimento, na prática é como se não existissem. É nesse sentido que Perrenoud sugere treinamentos de mobilização dos conhecimentos articulados a práticas analíticas, os quais buscariam transpor tais recursos, combiná-los, elaborar o problema e lançar mão de estratégias originais para resolvê-lo. No entanto, essa transferência não é automática, como se verá mais adiante.

Para Perrenoud (1999) a natureza do processo de mobilização dos recursos cognitivos ainda é de difícil compreensão, por isso, prefere usar o termo mobilização a transferência. A metáfora da mobilização ${ }^{9}$ contempla a reconstrução constante do conhecimento, não o considerando apenas como um objeto que se desloca. Sugere também uma dinamicidade quando se toma uma decisão diante de uma situação complexa, orquestrando recursos, experiências e saberes. A metáfora da mobilização considera o papel ativo do sujeito e suas intenções, mais que a transferência, embora esta não se limite apenas a aspectos mecânicos (Perrenoud, 1999a). Mesmo o termo "recursos a serem mobilizados", ou "recursos cognitivos", é mais conveniente que "saberes" e "saber-fazer", pois se pode recorrer a informações, saberes, esquemas,

8. No sentido de uma atividade prática ou não (estratégias e situações) com potencial de mobilizar recursos cognitivos.

9. Philippe Perrenoud trata a mobilização e a transferência como metáforas. 
capacidades, posturas, valores e atitudes, os quais são internos ao sujeito, além de recursos materiais externos. Segundo Perrenoud (1997), em uma abordagem antropológica e psicológica, a competência, enquanto capacidade de criar respostas, de aprender e de mobilizar aquisições, é uma característica dos seres humanos, capazes de gerenciar invariâncias e inovações. Um exemplo característico é o da linguagem. Embora o homem tenha a capacidade genética de falar, deve aprendê-la.

Conforme Perrenoud (1997), as competências permitem enfrentar com algum sucesso as situações desconhecidas porque contêm certa intuição analógica que possibilita a mobilização de vários recursos e experiências anteriores, a fim de obter uma resposta parcialmente original que seja adequada à situação. É nesse sentido que as competências se situam entre inovações e repetições. Entretanto, a escola impõe uma rotina ao trabalho do professor e ao papel do aluno, levando-os, na maior parte do tempo, a estratégias que objetivam apenas a aprovação em exames, o que entra em choque com alternativas metodológicas na perspectiva das competências (Perrenoud, 1997, 1999). Dessa forma, a escola age como se a mobilização dos saberes se desse espontaneamente, bastando para isso a imersão do aluno na complexidade do mundo, para que os saberes escolares se transformem em recursos mobilizáveis.

A questão do caráter transversal das competências ainda é um tema pouco explorado. Bernard Rey (2002) ressalta que a identidade de estruturas lógicas entre um problema que o aluno sabe resolver e um problema novo não provoca por si mesma a extensão da competência. Seria imaginar que essa identidade (um elemento do mundo) serviria de estímulo suficiente para a mobilização de recursos cognitivos do sujeito. Para Rey, "não existe capacidade transversal como realidade psicológica. Há, todavia, uma possibilidade de transferência ou de transversalidade: ela surge quando o sujeito toma consciência das suas próprias abordagens e das semelhanças entre as situações" (2002, p. 170).

O exame das próprias abordagens de um problema ou situação pode ser entendido como uma prática metacognitiva. Isso exige mais cuidado ao se olhar para o problema das competências, pois se insere também no campo da metacognição ao entendê-la como uma compreensão a respeito das formas de se chegar ao conhecimento, bem como a identificação das dificuldades de sua apreensão. Detectar a rede de obstáculos e representações que dificultam 
ou impedem o sujeito de compreender determinados saberes é que distingue a estratégia metacognitiva da estratégia cognitiva. Esta, por sua vez, consiste em relacionar saberes em fase de assimilação com aqueles já apreendidos. No entanto, tal distinção não é tão simples ${ }^{10}$.

O problema da transferência das competências e da mobilização de recursos cognitivos é discutido também por Gérard Fourez $(1999,2006)$. Para o autor, "transferir" pode ser entendido em didática como "utilizar uma competência, uma noção, um conceito fora de seu contexto de produção" (2006, p. 59). Ou seja, trata-se de recorrer a recursos para um novo fim, fora do contexto inicial. Mais adiante, Fourez destaca que "diante de uma mesma situação, existe uma infinidade de modelizações possíveis. Seu valor é relativo ao que se quer fazer com elas" (p. 109). Isso evidencia a impossibilidade de reduzir as competências aos saberes, desconsiderando-se, por exemplo, valores. Conforme Fourez pode-se falar de um potencial de transversalidade, uma vez que não existem garantias claras de que esta aconteça. No caso em que determinadas capacidades sejam transferidas para outros contextos, mesmo que com pequenas modificações, pode-se atribuir, nesse caso a característica transversal, entendida do seguinte modo:

A transversalidade não é vista como existente nela mesma, antes que seja construída. É em situações particulares que se desenvolvem as competências, métodos, modelos, noções ou conhecimentos, para, em seguida, transferi-los a outras classes de situações. Quando a transferência é realizada, ou mesmo padronizada, pode-se falar de modelo transversal, ou competência transversal. (Fourez, 1999, p. 5)

Fica clara aqui a relevância dos saberes como recursos mobilizáveis na construção das competências. Isso aponta para a inviabilidade da dicotomia entre competências e conteúdos. Menosprezar os conteúdos e centrar-se excessivamente sobre o sujeito é um dos pontos de fortes críticas às competências. Entretanto, a mudança de ênfase se refere às escolhas metodológicas e de conteúdos a serem ensinados, não se trata de diminuir a importância destes. Ao contrário, Perrenoud afirma que "os conhecimentos são indispen-

10. Rey (2002) prossegue essa discussão. 
sáveis para a inteligibilidade das observações e para a construção de hipóteses" (1999, p. 22), o que é fundamental, segundo o autor, para a construção de competências, entendidas, nesse caso, como gestoras dos conhecimentos, ou ainda, responsáveis por orquestrar um conjunto de esquemas.

Surge aqui uma outra questão: as competências não seriam, elas mesmas, os próprios esquemas? Para Perrenoud, não. $\bigcirc$ autor recorre a Gérard Vergnaud (1990) para identificar os esquemas como "estruturas invariantes de uma operação ou de uma ação" e destaca que as competências não se confundem com os recursos que mobilizam, pois acrescentam um certo valor de uso a estes, o que as diferencia de um conjunto de esquemas; estes sim entendidos como recursos mobilizáveis. As competências envolvem uma complexidade maior, pois comportam inferências, antecipações, generalizações, transposições analógicas, além de outras capacidades humanas. Nesse caso, uma competência também se torna um recurso mobilizável para a construção de outras competências mais complexas, ou mesmo para a aprendizagem de conteúdos específicos.

Assim, a identificação e a formalização de uma competência não se originam apenas nos saberes de referência de cada disciplina, ou no "saber sábio", para usar a terminologia de Chevallard (199|), mas também se encontram nas práticas sociais, que passam a ser referência de status equivalente aos saberes " . Isso exige, entre outras coisas, um profundo conhecimento da sociedade para a qual se está formando um determinado sujeito. Todavia, não significa assumir que as competências se reduzem às práticas cotidianas ou ao senso comum.

Entretanto, a construção de um programa escolar consistente não é tarefa fácil. De modo simplificado, pode-se chamar a atenção para a diferença e a distância que há entre o currículo prescrito e o currículo real, aquele que é implementado na sala de aula. Paralelamente a isso, constata-se que a maioria dos conhecimentos escolares acumulados é pouco útil para o cotidiano dos alunos, ao mesmo tempo em que a escola não é o único lugar para se adquirir competências. Haverá, portanto, a necessidade de privilegiar determinadas competências e saberes em detrimento de outras. Quais escolhas fazer?

I I. O termo equivalente aqui é relativo. Perrenoud ( 1998) destaca que saberes e práticas são de domínios e de realidades distintas e que as práticas mobilizam saberes, mas não se reduzem a estes. 
O problema maior não está no acúmulo de conhecimentos em si, mas na falta de estratégias e situações que levem os alunos a se servirem desses conhecimentos em suas vidas. Ou seja, o que está em discussão não é propriamente a pertinência dos saberes escolares, mas a ignorância em gerenciálos, mobilizá-los em situações cotidianas. As competências não se opõem aos saberes, mas ao mero acúmulo de informações e de pré-requisitos como fim. Além disso, capacidades descontextualizadas e com alto grau de abstração, supostamente ensinadas, como raciocinar, negociar, procurar informações, formular hipóteses, argumentar, entre outras, não dão consistência suficiente aos programas. Em muitos casos, mascaram práticas antigas, fazendo apenas referências a uma ação ou a uma aplicabilidade.

Expandir os currículos para competências gerais associadas a saberes específicos busca, na maioria das vezes, minimizar conflitos entre os defensores dos saberes disciplinares e os adeptos da cultura generalista. Para evitar falsas abordagens por competências, um programa estruturado nessa perspectiva terá que precisar o grau de abrangência das competências que pretende construir, ao mesmo tempo em que não deveria explicitar todas as competências e conteúdos de forma padronizada, tirando qualquer autonomia do professor. Para Perrenoud (1999), há necessidade de considerar os aspectos aproximativos dos recursos mobilizados em determinada situação-problema como uma característica da própria lógica da ação. Isso, de certa forma, põe a formação por competências em oposição à educação bancária, denunciada por Paulo Freire, na qual o professor faz o saque daquilo que depositou na cabeça dos alunos a cada avaliação. Há uma dimensão desafiadora nas competências, para a qual o professor deverá se acostumar a trabalhar com problemas.

Philippe Perrenoud propõe que o ensino por competências deveria promover uma "aventura intelectual" nos alunos e nos professores, no sentido de se opor à excessiva fragmentação e inflexibilidade comuns à pedagogia por objetivos, na qual se sabe exatamente como começará e como terminará o ano letivo. É esse mecanismo burocrático que a noção de competências procura romper. Isso exigirá um planejamento flexível e com escolhas didáticas que tenham um potencial para explorar e confrontar os alunos com obstáculos impostos pelos novos aprendizados. $\bigcirc$ trabalho com situações-problema'12, por

12. Philippe Meirieu dá uma boa definição para situação-problema: "situação didática na qual 
exemplo, torna-se um bom momento para aprender não apenas os conteúdos, mas sua gestão. Além disso, o professor terá que avaliar frequentemente suas escolhas didáticas e eleger conteúdos relevantes, em oposição a extensas listas, recorrendo constantemente às referências dos saberes escolares e suas fontes de transposição "ousando extrair o essencial, para não se perder no labirinto dos conhecimentos". Para enfatizar seus argumentos, o autor destaca que:

A abordagem por competências leva a fazer menos coisas, a dedicar-se a um pequeno número de situações fortes e fecundas, que produzem aprendizados e giram em torno de importantes conhecimentos. Isso obriga a abrir mão de boa parte dos conteúdos tidos, ainda hoje, como indispensáveis. (Perrenoud, 1999, p.64)

Fica claro, portanto, que as competências não esvaziam a escola de conteúdos, ao contrário, estes passam a ser trabalhados com mais profundidade e com significado para os alunos, pois terão alguma relação com situações para as quais são instrumentos fundamentais na busca de soluções. Também não implica abandonar as disciplinas rumo a uma unificação utópica, mas em aproveitá-las melhor, fazendo com que as especialidades evitem abordagens superficiais em qualquer situação de aprendizagem. Em síntese, um ensino por competências pretende questionar o projeto escolar.

\section{OS SABERES E AS PRÁTICAS EM QUESTÃO}

Qualquer reforma educacional da dimensão sugerida pelas DCNEM encontrará vários obstáculos para sua implementação e certamente não poderá ignorar a inércia dos sistemas de ensino. Ao mesmo tempo, as discussões precedentes indicam que ao pensar uma formação por competências a escola é colocada à prova. A isso se soma o alerta de Philippe Perrenoud ao afirmar que os jovens "acreditam cada vez menos que o sucesso escolar irá protegêlos das dificuldades da existência. Assim, pede-se à escola que instrua uma

se propõe ao sujeito uma tarefa que ele não pode realizar sem efetuar uma aprendizagem precisa. Esta aprendizagem, que constitui o verdadeiro objetivo da situação-problema, se dá ao vencer o obstáculo na realização da tarefa" (Meirieu, 1998, p. 192). 
juventude cuja adesão ao projeto de escolarização não está mais garantida" ( 1999 , p. I 5). Tal cenário impõe à escola a revisão de seu papel na construção de uma sociedade, que busca, de certo modo, compreender o momento histórico e econômico-social no qual se encontra. Mais especificamente, as práticas educacionais e os saberes ensinados revelam fragilidades para lidar com as novas demandas sociais.

Esse desafio se torna maior na medida em que ocorre no Brasil um aumento crescente do acesso e da procura à educação formal, identificado inclusive nas DCNEM. Mas, conforme destaca Meirieu ( 1998), não teria ocorrido uma democratização da escola, senão uma massificação. Ou seja, com o pretexto de oferecer a todos as mesmas oportunidades, foram adotados os mesmos modelos pedagógicos que antes formavam uma parcela dos jovens das classes mais favorecidas que iriam prosseguir nos estudos. Portanto, a garantia de acesso ao ensino formal não implica a conquista de uma formação que atenda aos projetos pessoais e coletivos. Por outro lado, há muito a ser feito no interior da sala de aula, especialmente em relação aos saberes escolares e às práticas que buscam levar os alunos à apreensão desses saberes. Torna-se, desse modo, fundamental o papel do professor como protagonista do processo.

Entre as várias consequências desse novo cenário educacional vale destacar a ampliação da heterogeneidade na sala de aula. Administrar isso didaticamente passa a ser um desafio para o professor, notadamente em um ensino por competências. Ao mesmo tempo em que a noção de competências vem para assegurar a adesão dos alunos ao projeto escolar, pode fazer aumentar a heterogeneidade entre eles, pois exige mais abstração e mais iniciativa, se comparada às práticas escolares clássicas, apoiando-se em saberes de alto nível (Perrenoud, 1999). É desnecessário dizer que o acesso à informação é decisivo e que um programa por ele mesmo não resolve o problema das desigualdades presentes no contexto escolar.

Uma das exigências para o professor nesse novo cenário é a prática reflexiva, como condição necessária para se construir novos saberes e garantir a reflexão sobre suas experiências. Embora esse tema já tenha sido discutido por várias correntes educacionais, como a pesquisa-ação, o professor pesquisador, o professor reflexivo, pretende-se chamar a atenção neste caso para a necessidade de uma epistemologia da prática docente, conforme a defende Maurice Tardif (2000, 2002). Trata-se de superar a noção de experiência como 
o mero acúmulo de realizações sucessivas e rever as representações que assumem status de verdade na mente dos professores, tornando-se verdadeiros obstáculos para inovações.

Essas representações se constroem predominantemente no exercício profissional e têm tanto um caráter subjetivo como coletivo, pois as experiências são compartilhadas com os pares e encontram sua legitimidade na prática. Assim, a revisão e a reorientação das práticas é penosa para o professor, uma vez que se estaria pedindo para abandonar uma gama de ações que garantiu até o presente momento sua sobrevivência no ambiente escolar, ainda que os resultados sejam questionáveis. Tardif (2000) defende a necessidade de transformar a prática profissional em objeto de pesquisa. Para isso chama de epistemologia da prática profissional "o estudo do conjunto dos saberes utilizados realmente pelos profissionais em seu espaço de trabalho cotidiano para desempenhar todas as suas tarefas" (Tardif, 2000, p. 10). Nesse sentido, uma epistemologia da prática comportaria também a reflexão sobre a ação e para a ação, o que Perrenoud (2002) chama de prática reflexiva, uma vez que os problemas encontrados nesse contexto não podem ser resolvidos apenas com os saberes teóricos. Todavia, o autor não desconsidera a relevância da busca de saberes didáticos teóricos para "equipar o olhar e a reflexão sobre a realidade" (Perrenoud, 2002, p. 17).

A prática reflexiva como atitude profissional não tem fim e adquire seu maior sentido quando, após realizada a ação, possibilita a compreensão e a transformação das experiências em novos saberes capazes de serem mobilizados em diferentes contextos. Essa é a expressão da competência crítico-analítica do professor a respeito de sua própria prática. No entanto, tal reflexão não se dará no vazio, conforme ressalta Perrenoud:

Não é possível avançar muito se refletirmos ou debatermos sem recorrermos a certos saberes. A experiência singular só produz aprendizagens se ela estiver estruturada em conceitos, se estiver vinculada a saberes que a tornam inteligível e inserem-se em alguma forma de regularidade. (2002, p. 52)

Esse argumento reforça a importância de instrumentos teóricos capazes de iluminar as práticas docentes e seus problemas. Não se trata, portanto, de aplicar a teoria na prática, mas de mudar a própria prática e de não cair na 
armadilha de que basta o novo ser assimilado para ser implementado na sala de aula. A compreensão e a análise da prática é que possibilitará reorientá-la com vistas a objetivos mais amplos. Espera-se, desse modo, levar o professor a colocar suas ações como parte do problema.

A elevação de status da epistemologia da prática defendida por Tardif (2000, 2002), por Perrenoud (1999, 2002), Perrenoud et al. (2002) e por Meirieu (1998), se bem que com nuanças diferentes, assegura a tomada de consciência desses saberes, muitas vezes implícitos, que se apóiam em argumentos subjetivos, mas que também possuem uma dimensão social, pois se constroem em situações coletivas de trabalho e carregam ainda as experiências anteriores dos professores, vividas como alunos, antes mesmo da formação inicial. Assim, tais saberes práticos se caracterizam por uma dimensão individual e social.

A visibilidade desses saberes, no entanto, não é tarefa fácil. Como os professores têm certa dificuldade em abstrair suas experiências, esses saberes são mais bem definidos como saberes práticos e não saberes da e a respeito da prática. Conforme Tardif, são saberes que refletem "muito mais consciência no trabalho do que consciência sobre o trabalho" (2002, p. II0). Mas, são também saberes existenciais, pois estão impregnados com a história de vida dos professores e têm um caráter não analítico. Paradoxalmente, tais saberes são parâmetros para juízos de valor e de escolhas didáticas, cuja validação se deu na atividade profissional diária. Além disso, esses saberes caracterizam um modelo simplificado da prática que, associados a uma organização escolar que impõe um conjunto de ações rotineiras tanto dos professores como dos alunos, conduz a um ensino burocrático, "cuja pertinência social não é mais óbvia" (Tardif, 2002, p.47). Isso explica a dificuldade de superar velhas práticas.

A desvalorização dos saberes transmitidos na escola pode acirrar dicotomias que geram tensões no projeto escolar, tais como: formação versus informação, cultura geral versus utilitarismo, formação geral versus formação específica. Uma das principais críticas às DCNEM se encontra nesse contexto: a de se subordinar ao mercado, levando a uma "lógica de consumo dos saberes escolares", conforme a descreve Tardif (2002).

$\mathrm{Na}$ contracorrente dessa lógica, os PCN e PCN+ afirmam que a compreensão e a intervenção no mundo deveriam estar entre as principais metas do ensino médio. Assim, os saberes escolares e as práticas que (supostamente) 
levam aos seus aprendizados estariam à prova, uma vez que sua pertinência em promover a aproximação entre o mundo e o aluno desaparece no instante em que a situação escolar que os gerou tenha cessado. Aprender e compreender o mundo nesse caso consiste em trazer uma parcela deste para o universo do aluno e construir um conjunto de representações que ofereçam a possibilidade de ação sobre esse mundo (Meirieu, 1998). Sem cair em um utilitarismo estrito, ressalta o autor, isso estaria relacionado a um projeto de utilização do que se aprende e que proporcionaria ao aluno uma finalidade àquelas representações como potencialmente aptas a serem mobilizadas em novas situações.

Desse modo, segundo Meirieu ( 1998 ), o conhecimento não poderia ser entendido como um produto de compra, pois toda a história de apropriação dos conhecimentos seria negada, o que levaria a reduzir o ensino ao acúmulo de informações. Negligenciar essa dimensão temporal da construção das representações sobre o mundo implica assumir a mera transmissão de saberes como elemento suficiente da aprendizagem. Nesse sentido, as competências se colocam em posição contrária à pedagogia da informação.

Em uma pedagogia centrada na transmissão e na informação, buscam-se assegurar as condições de emergência dos resultados sem, contudo, preocuparse com as operações mentais empreendidas. Uma prática educacional que adote a verificação da aprendizagem apenas em situações escolares que supostamente a tenham gerado, bastando a repetição e a imitação, revela comportamentos e não necessariamente as operações mentais que integrariam novos elementos às estruturas já existentes. Para isso, se exige somente uma atitude receptiva dos alunos e se assume que basta tal condição para que ocorra a aprendizagem. Não é isso que se entende aqui por adesão ao projeto escolar. Além disso, a sobreposição dos saberes escolares aos conhecimentos anteriores dos alunos não garante a aprendizagem, pois os saberes oriundos das experiências pessoais estão mais próximos do mundo do sujeito, que acaba abandonando os saberes a ele transmitido tão logo esteja fora da sala de aula.

\section{CONSIDERAÇÕES FINAIS}

As críticas que vêm da Sociologia do trabalho em relação à institucionalização da noção de competências na escola revelam que não se trata de um mero efeito de moda, mas apontam mudanças sociais significativas, em 
especial na relação de produção e na relação entre trabalho e escola. Todavia, é preciso considerar que se trata de contextos distintos e expressam uma face do problema. Sua transposição, portanto, deverá ser feita com cautela.

Na perspectiva da "lógica das competências", conforme foi discutido anteriormente, o trabalhador pertence à empresa e tem liberdade para fazer tudo o que the é permitido. Ou seja, é uma forma de autonomia vigiada, inclusive para negociar individualmente o valor de sua competência expressa em remuneração, desconsiderando ou enfraquecendo a categoria. Entretanto, sua liberdade passa a ser menor ainda, na medida em que suas competências profissionais, que são seu bem de troca, só têm validade assegurada na empresa. Diante de tantas incertezas, a construção do conhecimento se confunde com a adaptação do indivíduo ao ambiente e seus conhecimentos serão tão verdadeiros quanto mais eficazes se mostrarem. Dito de outro modo: a eficácia dos saberes assume status de verdade. Esse cenário expressa o que se poderia chamar de uma privatização do indivíduo.

No entanto, a definição e a implementação de uma pedagogia das competências, que obedeçam a essa lógica, ainda não estão consolidadas, conforme Ramos (200I). Há possibilidades de se buscar a construção de uma compreensão das competências que supere as fragilidades dos sistemas de formação, geral e/ou profissional, e que seja favorável aos trabalhadores, os mais atingidos. Para isso, a escola terá que ficar atenta às mudanças sociais, pois as competências exigidas podem dar ao sujeito os meios de sobrevivência no mercado, mas podem também fazê-lo identificar e compreender os limites que o impedem de superar as condições atuais. Assim, se torna fundamental a ampliação das discussões a respeito das competências, a fim de que estas não sejam confundidas ou limitadas a generalidades e deixem de avançar além do espontaneísmo e do senso comum. Ao contrário, a superação destes é que seria o objetivo principal.

ensino por competências, no entanto, também pode ser discutido com base em uma abordagem didática, subentendendo seus domínios epistemológicos, psicológicos e praxeológicos. Nesse caso são questionados os saberes escolares bem como as finalidades da escola, especialmente ao serem identificados com a necessidade de se colocar a escola em perspectiva. Ou seja, de pensar o projeto escolar para uma etapa posterior, para quando o aluno não estiver mais sob a tutela do professor. Assim, as competências também 
adquirem a forma de um importante instrumento e parâmetro de análise dos saberes escolares e das escolhas didáticas feitas pelo professor, ao mesmo tempo em que denunciam uma falsa familiaridade com os conteúdos de ensino. Essa contribuição consiste em transpor a noção de competências para o ensino das disciplinas escolares, pois é nesse contexto em que se dará sua implementação. Todavia, tal transposição também deverá ser feita com cuidado, pois pode não se aplicar em novos contextos se suas origens forem esquecidas e suas características negligenciadas. Tardif (2002) e Perrenoud (2002) mostraram as influências das representações dos professores nas práticas docentes.

Ao mesmo tempo em que as DCNEM sugerem uma estrutura curricular na perspectiva das competências, não houve uma discussão teórica que apresentasse a noção de competência como alternativa didática viável para enfrentar os problemas de ensino e aprendizagem. Segundo Silva (2008), "as distintas formas de expressar o que se há de entender por competências evidenciam as ambiguidades presentes em documentos e proposições oficiais" (p. I 40). Ricardo (2002) e Ricardo e Zylbersztajn (2002, 2007, 2008) ressaltam que isso causou mais problemas aos professores do ensino médio que solução, pois a proposta não foi compreendida, ocorrendo na maioria das vezes um mascaramento de práticas antigas. As pesquisas de Santos, Campos e Almeida (2005) e Silva (2008) apontam na mesma direção.

Diante disso, a educação deveria buscar a ampliação dos objetivos dos alunos, para além da satisfação das suas exigências espontâneas, promovendo necessidades intelectuais cada vez mais enriquecedoras, gerando novas aprendizagens e novas inquietações pelos saberes culturais (Duarte, 2000). Desse modo, não caberia colocar a noção de competências em meio a falsas dicotomias, como competências versus conteúdos, cultura geral versus utilitarismo ou teoria versus prática. Ao contrário, todas essas dimensões dos saberes integram as competências que são pertinentes tanto quanto responderem a situações desconhecidas.

A dissociação entre conteúdos (saberes) e escolhas metodológicas não parece, no entanto, viável em um ensino por competências, pois as ações didático-pedagógicas podem-se reduzir, por exemplo, a informações ou ao acúmulo de dados, como se por si só garantissem a construção de competências. Assim, não só os saberes escolares, mas também as práticas docentes estão à prova, e as representações e saberes dos professores carecem de um grau 
analítico que superem o caráter meramente discursivo. Pretende-se, portanto, transformar a prática em objeto de análise e crítica, além dos pressupostos e das possíveis mudanças desencadeadas pela reflexão dos documentos oficiais. Essa exigência é necessária para que, conforme Silva (2008), "não se incorra numa adesão cega ou numa resistência fruto da ignorância" (p. 102). É nessa perspectiva que este trabalho espera contribuir.

\section{REFERÊNCIAS BIBLIOGRÁFICAS}

ARRUDA, M. C. C. Qualificação versus competência. Boletim Técnico do Senac, Rio de Janeiro, v. 26, n. 2, p. 19-27, maio/ago. 2000.

BRASIL. Ministério da Educação. Orientações curriculares para o ensino médio: ciências da natureza, matemática e suas tecnologias, 2. Brasilia: SEB, 2006.

. Parâmetros curriculares nacionais: ensino médio. Brasília: Semtec, 1999.

.PCN + ensino médio: orientações educacionais complementares aos Parâmetros Curriculares Nacionais. Ciências da natureza, matemática e suas tecnologias. Brasília: Semtec, 2002.

CHEVALLARD, Y. La Transposición didáctica: del saber sabio al saber enseñado. Buenos Aires: Aique, 1991.

DELUIZ, D. O Modelo das competências profissionais no mundo do trabalho e na educação: implicações para o currículo. Boletim Técnico do Senac, Rio de Janeiro, v.27, n.3, p. 13-25, set./dez. 2001 .

DUARTE, N. Vigotski e o "aprender a aprender": críticas às apropriações neoliberais e pósmodernas da teoria vigotskiana. Campinas: Autores Associados, 2000.

DURAND, J.-P. O Modelo da competência: uma nova roupagem para velhas ideias. Revista Latinoamericana de Estudios del Trabajo, México, v. 7, n. I4, p. 203-228, 2001.

FOUREZ, G. Compétences, contenus, capacites et autres casse-têtes. Forum, p.26-31 , maio 1999. Disponível em: <www.sciences.fundp.ac.be/scphilosoc/cethes/stliteracySSS.html>. Acesso em: 8 fev. 2004.

. (Org.). Des compétences négligées par l'école: les raconter pour les enseigner. Bruxelles: Couleur Livres, 2006.

HESSEN, J. Teoría del conocimiento. México: Purrúa, 1994.

MACHADO, L. A Institucionalização da lógica das competências no Brasil. Pró-Posições, Campinas, v. 13, n. I, p. 92-110, jan./abr. 2002. 
. "Modelo de competências" e a regulamentação da base curricular nacional e de organização do ensino médio. Trabalho e Educação, Belo Horizonte, n. 4, p. 79-95, ago./dez. 1998.

MEIRIEU, P. Aprender... sim, mas como? 7. ed. Porto Alegre: Artes Médicas, 1998.

PERRENOUD, P. L'Approche par compétences durant la scolarité obligatoire: effet de mode ou réponse décisive à l'échec scolaire? In: PERRENOUD, P. Construire des compétences dès l'école. Paris, ESF, 1997. p.93-I I0. Disponível em: < http://www.unige.ch/fapse/SSE/teachers/ perrenoud/php_main/textes.html>. Acesso em: I I abr. 2003.

. Construir as competências desde a escola. Porto Alegre: Artes Médicas Sul, 1999.

- A Prática reflexiva no ofício de professor: profissionalização e razão pedagógica. Porto Alegre: Artmed, 2002.

. Transférer ou mobiliser ses connaissances? D'une métaphore l'autre: implications sociologiques et pédagogiques. In: COLLOQUE DE RAISONS ÉDUCATIVES SUR LES COMPÉTENCES, mais 1999, Genève. Communication... Genève: Faculté de Psychologie et des Sciences de l'Éducation, 1999a. Disponível em:<http://www.unige.ch/fapse/SSE/ teachers/perrenoud/php_main/textes.html>. Acesso em: II abr. 2003.

. La Transposition didactique à partir des pratiques: des savoirs aux compétences. Revue des Sciences de l'Éducation, Montreal, v.24, n.3, p.487-5।4, 1998. Disponível em: $<$ http://www.unige.ch/fapse/SEE/teachers/perrenoud/php_main/textes.html>. Acesso em: | | abr. 2003.

PERRENOUD, P. et al. As Competências para ensinar no século XXI: a formação dos professores e o desafio da avaliação. Porto Alegre: Artmed, 2002.

RAMOS, M. N. A Pedagogia das competências: autonomia ou adaptação? São Paulo: Cortez, 2001 .

REY, B. As Competências transversais em questão. Porto Alegre: Artmed, 2002.

RICARDO, E. C. As Ciências no ensino médio e os Parâmetros Curriculares Nacionais: da proposta à prática. Ensaio: Avaliação e Políticas Públicas em Educação, Rio de Janeiro, v. I0, n.35, p. $|4|-160,2002$.

RICARDO, E. C.; CUSTÓDIO, J. F; REZENDE JUNIOR, M. F. Comentários sobre as Orientações Curriculares de 2006 para o ensino de física. Revista Brasileira de Ensino de Física, v. 30, n. 2, jun. de 2008. Disponível em: <http:www.sbfisica.org.br/rber/pdf/30240 I . pdf>. Acesso em: ago. 2008. 
RICARDO, E. C.; ZYLBERSZTAJN, A. O Ensino das ciências no nível médio: um estudo sobre as dificuldades na implementação dos Parâmetros Curriculares Nacionais. Caderno Brasileiro de Ensino de Física, Florianópolis, v. 19, n.3, p.35।-370, dez. 2002.

. Os Parâmetros Curriculares Nacionais na formação inicial dos professores das Ciências da Natureza e Matemática do ensino médio. Investigações em Ensino de Ciências, Porto Alegre, v. I2, n.3, p.339-355, dez. 2007.

. Os Parâmetros Curriculares Nacionais para as Ciências do Ensino Médio: uma análise a partir da visão de seus elaboradores. Investigações em Ensino de Ciências, Porto Alegre, v. 13, n.3, p. 257-274, 2008.

ROPÉ, F.; TANGUY, L. (Org.). Saberes e competências: o uso de tais noções na escola e na empresa. Campinas: Papirus, 1997.

SANTOS, V. T, CAMPOS, Â. F; ALMEIDA, M. Â. V. Concepções dos(as) professores(as) de química sobre o desenvolvimento de competências na escola. Ensaio: Pesquisa em Educação e Ciências, Belo Horizonte, v. 7, n. I, p. 33-46, jul. 2005.

SILVA, M. R. Currículo e competências: a formação administrada. São Paulo: Cortez, 2008.

TANGUY, L. Competências e integração social na empresa. In: ROPÉ, F; TANGUY, L. (Org.). Saberes e competências: o uso de tais noções na escola e na empresa. Campinas: Papirus, 1997. p. I5-24.

TARDIF, M. Saberes docentes e formação profissional. 2. ed. Petrópolis: Vozes, 2002. - Saberes profissionais dos professores e conhecimentos universitários: elementos para uma epistemologia da prática profissional dos professores e suas consequências em relação à formação para o magistério. Revista Brasileira de Educação, Rio de Janeiro, n. I3, p. 5-13, jan./abr. 2000.

VERGNAUD, G. La Théorie des champs conceptuels. Recherches en Didactique des Mathématiques, Grenoble, v.10, n. 2/3, p.133-170, 1990.

Recebido em: outubro 2008

Aprovado para publicação em: fevereiro 2010 